\title{
An Innovative Approach in Balancing Real Power Using Plug in Hybrid Electric Vehicles
}

\author{
Andrew D. Clarke, Elham B. Makram \\ Department of Electrical and Computer Engineering, Clemson University, Clemson, USA \\ Email: adclark@g.clemson.edu, makram@clemson.edu
}

Received 10 August 2014; revised 10 September 2014; accepted 24 September 2014

Copyright (C) 2014 by authors and Scientific Research Publishing Inc.

This work is licensed under the Creative Commons Attribution International License (CC BY). http://creativecommons.org/licenses/by/4.0/

c) (i) Open Access

\begin{abstract}
Many distribution systems operate under unbalanced loading conditions due to the connection of single phase loads to a three phase system. As PHEVs become more prevalent, it is expected that this unbalance will be further exacerbated due to the power draws from single phase chargers. Unbalanced loads reduce the overall system operating efficiency and power transfer capability of assets. In this paper, a new method of mitigating real power unbalance is suggested. It works by selecting which of the three phases that each single phase PHEV charger in a car park should be connected to. The algorithm is then tested on a simulation model of a real world distribution system. Using the balancing algorithm, balancing of the real power flowing through the feeder to the car park is accomplished.
\end{abstract}

\section{Keywords}

Unbalance, Electric Vehicles, Power Distribution, Power System Control, Power System Modeling

\section{Introduction}

Many distribution systems are inherently unbalanced due to their configuration. Balancing of distribution systems is often attempted by spreading single phase loads across the three phases by electric utilities however unbalance is still common due to variation of the single phase loads. This unbalance is expected to be further amplified by the connection of single phase Plug In Hybrid Electric Vehicle (PHEV) chargers which has the potential to negatively impact existing assets [1]. This is due in part to the unequal connection of PHEVs to the three phases of the electric distribution system [2]. Many current studies attempt to examine the effects of PHEVs on distribution systems, however most neglect the important impacts PHEVs have on unbalance in a three phase system and the potential of using PHEVs to reduce unbalance. The contribution of this paper is using PHEVs to balance phases. Unbalance in a system may not necessarily harm the system by itself, but it is certainly not the 
most efficient way to operate. The unbalance conditions discussed in this paper deal with the unequal real power consumption of loads throughout the system. Whenever unbalance exists in a distribution system, negative and zero sequence currents are generated. Neither of these are usually desired in power systems however. Unbalance in a system can reduce power transfer capability of equipment, increase losses, interfere with fault protection devices, and produce overheating in motors and transformers [3] [4].

In a distribution system, if this unbalance condition is mitigated, potential problems can be avoided. The goal of this paper is to balance the real power while allowing PHEV charging and discharging operations to continue virtually unaffected. PHEV chargers represent a large, controllable, single phase load. In a large car park, it is expected that a three phase supply will be available, with vehicles distributed between the phases. Currently, it is not possible to force users to charge from a particular phase. A new idea that compensates for unbalance by allowing PHEV chargers in a car park to automatically change the phase they are drawing power from based on power flows in a distribution system is presented in this paper. An algorithm is then tested using a simulated unbalanced distribution system with a car park containing PHEV chargers.

The structure of this paper is as follows: Section 2 contains details of the PHEV model used for this study; Section 3 contains specifics of the distribution system being simulated, which in this case represents the Clemson University distribution system; Section 4 has details on the real power balancing using PHEVs; Section 5 has the results of simulations; and Section 6 contains the final conclusion of this paper.

\section{PHEV Model}

With the high cost of fossil fuels and the recent push to make automobiles more environmentally friendly, many manufacturers have started making PHEVs. According to [5], the IEEE places three criteria on a vehicle in order for it to fall under the classification of a PHEV.

1) The vehicle must have a battery with a capacity of at least $4 \mathrm{kWh}$ that is used to drive the vehicle.

2) The vehicle must be able to be recharged from the electric grid.

3) The vehicle must be capable of traveling at least 10 miles on battery power alone.

Most AC PHEV chargers fall into one of the three categories listed in Table 1 [6]. Based on the expectation that level 1 and 2 chargers will utilize commonly available building wiring, level 3 charging will not be considered in this paper. Due to the higher power transfer available with level 2 charging, which in turn typically leads to a faster recharge than level 1 charging, it is expected that most consumers will desire this type of charger if available. Based on [7], it is shown that a single phase PHEV charger can be developed with the capability of operating at a commanded real and reactive power. In order to decrease simulation time compared with a full switching model, which requires a very small time step, it is assumed that the desired current can be obtained using a PHEV charger. Therefore, a current source is used in place of a PHEV charger. The current is calculated based on the measured terminal voltage and commanded real and reactive powers using Equation (1), where $I_{\text {peak }}$ is the peak phasor value of current solved for, $V_{\text {peak }}$ is the measured peak voltage phasor, $P$ is the real power, and $Q$ is the reactive power.

$$
I_{\text {peak }}=\frac{2(P+j Q)^{*}}{V_{\text {peak }}^{*}}
$$

The model used for simulation purposes is allowed to consume or supply power up to $7 \mathrm{~kW}$, which is representative of a level 1 or level 2 PHEV AC charger [6]. The power for each PHEV is chosen between $0-7 \mathrm{~kW}$ charging or discharging power using a pseudorandom function in MATLAB to simulate volatility in PHEV availability and charging patterns.

\section{Clemson University Distribution System}

For this study, the Clemson University electric distribution system is modeled in Sim Power Systems, an add-on toolbox for MATLAB. A system diagram can be found in Figure 1. Parameters used were provided by Clemson University Utility Services. Due to the large amount of data corresponding to a system this size, inclusion of all system parameters is not feasible in this paper. The system is a primarily three phase, $12.47 \mathrm{kV}$ distribution system connected by underground tape shielded cables. The system is fed by a connection to a $44 \mathrm{kV}$ transmission system. At peak load for 2013, the system was drawing 22.03 MVA of three phase apparent power. Most buildings on campus are fed by three phase distribution transformers that step the voltage down to either $480 \mathrm{~V}$ or 


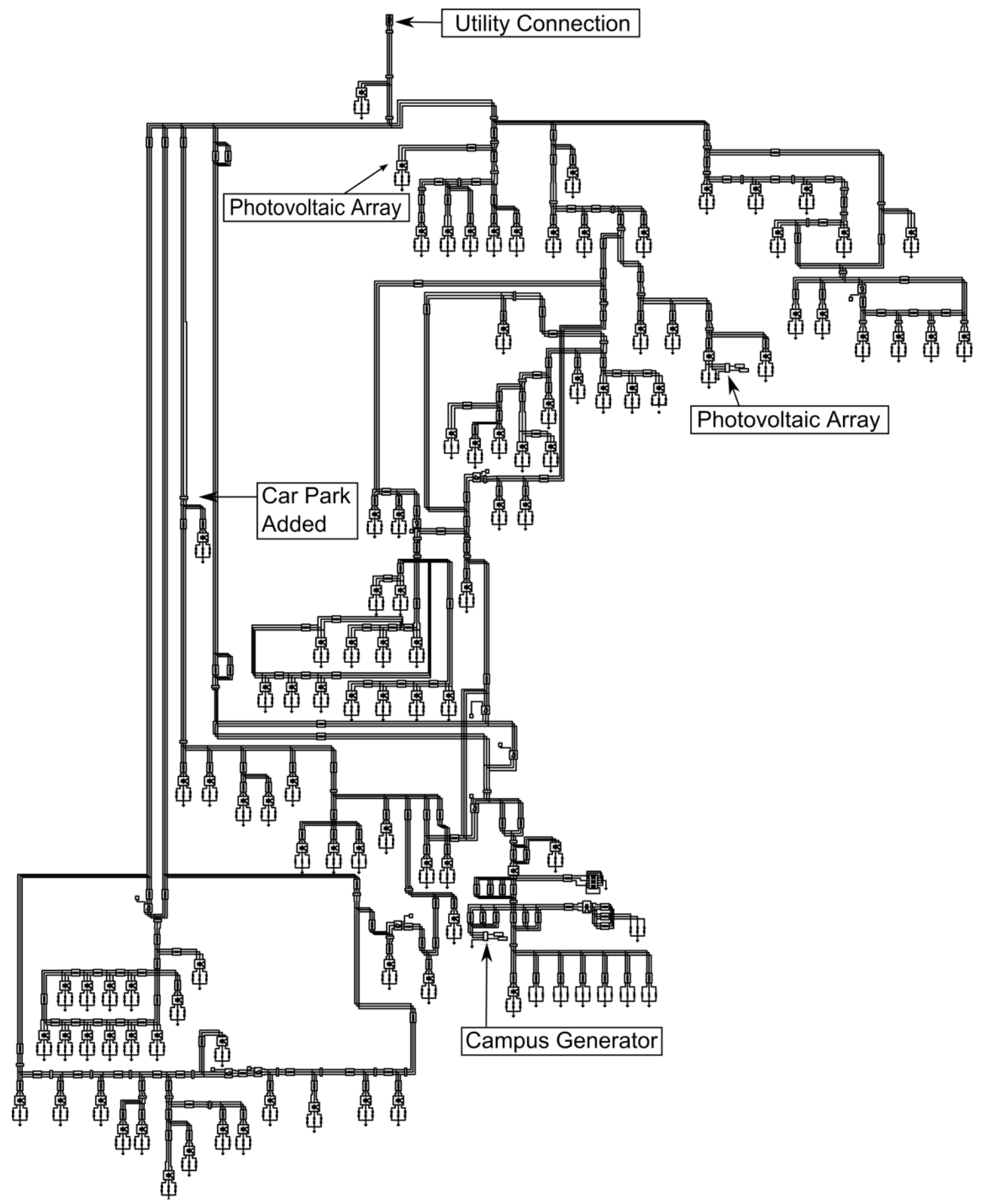

Figure 1. Clemson university electric distribution system.

Table 1. PHEV charging levels [6].

\begin{tabular}{|c|c|c|c|}
\hline Charging level & Nominal supply voltage & Maximum current & Continuous input power \\
\hline 1 & $120 \mathrm{~V}, 1$ phase & $12 \mathrm{~A}$ & $1.44 \mathrm{~kW}$ \\
\hline 2 & 208 - $240 \mathrm{~V}, 1$ phase & $32 \mathrm{~A}$ & $6.66-7.68 \mathrm{~kW}$ \\
\hline 3 & $208-600$ V, 3 phase & $400 \mathrm{~A}$ & $>7.68 \mathrm{~kW}$ \\
\hline
\end{tabular}


$208 \mathrm{~V}$. There are also two $15 \mathrm{~kW}$ photovoltaic arrays and a 5.5 MVA gas turbine used for peak load shaving.

In order to test the balancing algorithm, an unbalanced load is applied to the system. The powers of all the loads connected to phase A are increased by $2 \%$, the powers of all the loads connected to phase B are increased by $1 \%$, and the powers of all the loads connected to phase $\mathrm{C}$ are decreased by $3 \%$, all compared to balanced conditions. It is important to note however that these loads are connected on the secondary sides of the distribution transformers, some of which are Delta-Wye connected. This causes the unbalance in the system to appear on different feeders compared to the unbalance in the loads.

A PHEV car park is added to the campus system simulation at one of the major parking lots on campus to show the capability of using PHEVs to balance phases. A total of up to 30 PHEV charging stations are connected to the system in the car park at a given time, based on the power drawn by each PHEV and the algorithm described in this paper. The car park is connected to the system using a Wye Grounded-Wye Grounded three phase transformer. This transformer type is chosen because the balancing algorithm described in this paper intentionally unbalances the PHEV load on the secondary of this transformer in order to balance the real power flowing elsewhere in the system. Using a Wye Grounded-Wye Grounded three phase transformer allows the unbalanced power on one phase of the secondary to not influence another phase on the primary side of the transformer.

\section{Real Power Balancing Using PHEVs}

The goal of this idea is to automatically change the phase that PHEV chargers are connected to based on measured power flows in the system. Some vehicle chargers that are drawing power will be switched to the less heavily loaded of the three phases and some vehicle chargers that are supplying power will be switched to more heavily loaded phases. The effect of this is shifting some power away from heavily loaded phases. This in turn increases power on lightly loaded phases in order to balance the three phases as necessary. To accomplish this, the algorithm described in this section works by taking in information from each charger about how much real power it is drawing and responding with what phase each PHEV charger should be connected to. It also requires an input of the unbalanced real power measured where the balancing occurs. In order to be successful, the PHEVs must draw their power from where the algorithm will balance power.

In addition to the description given in this section, Figure 2 shows a flowchart of this algorithm. Once a specified time delay between calculations has passed, an approximation of the real power that would flow through each phase without the connection of PHEVs is calculated using Equation (2). The real power measured from the system is required by the algorithm. The real power consumed by each charger and memory of which phase each PHEV charger is connected to from the previous time step are also required. By neglecting the feeder losses caused by the addition of the PHEV to a phase, Equation (2) can be used. However, the losses caused by the addition of a PHEV to a phase are anticipated to be much smaller than the power drawn by the PHEV charger.

$$
P_{\text {Estimate Phase }}=P_{\text {Measured phase }}-\sum_{x \in \text { Phase }} P_{\text {PHEV }}(x)
$$

The estimated values of real powers for each phase without PHEVs connected are compared with the values from the previous calculation. If the estimated real power has not changed by a certain percentage and no PHEVs have been connected or disconnected since the last placement, the algorithm exits and waits for the specified time before starting over. If the estimated real power has changed or a PHEV has been connected or disconnected since the last placement, the algorithm is allowed to continue and the PHEVs are then sorted into a list based on the absolute value of the power consumed or supplied by each charger, with the largest listed first. Starting with the first power in the sorted list, the real power of the PHEV charger associated with it is checked to determine if it is drawing real power, supplying real power, or neither. If the PHEV charger is drawing real power, it is assigned a connection to the phase with the minimum estimated real power. This will cause an increase in the observed real power load on that phase. If the PHEV charger is supplying real power, it is assigned a connection to the phase with the maximum estimated real power. This will cause a decrease in the observed real power load on that phase. If the PHEV charger is neither drawing nor supplying real power, it is disconnected from the system. Based on the assigned phase connection, the estimated real power is recalculated using Equation (3).

$$
P_{\text {EstimateNew }_{\text {Phase }}}=P_{\text {Estimate Phase }}+P_{\text {PHEV }}(x)
$$




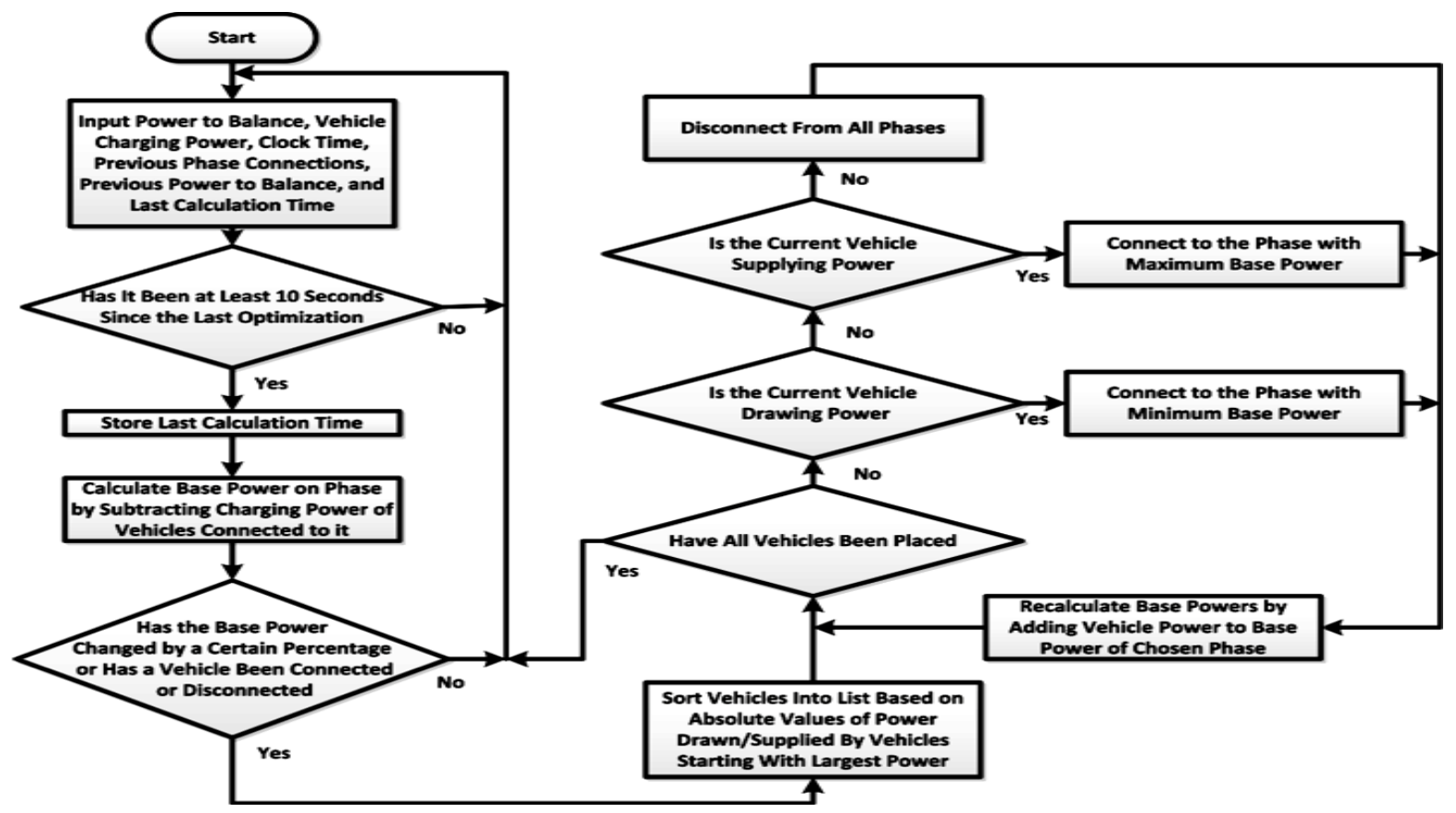

Figure 2. Real power balancing algorithm.

This assignment will continue until all PHEVs in the sorted list are placed. The switching elements connected to the PHEV chargers are then commanded to automatically switch without user interaction. As a result, this algorithm will exit and wait for the specified time before starting over. The time before the next calculation is based on a tradeoff. By increasing the time before the next calculation, wear on the switching elements will be reduced. By decreasing the time before the next calculation, the accuracy will be increased and PHEVs will be allowed to begin charging faster after connection to a charger. Due to the automatic switching used, the vehicles will continue to charge or discharge even if they are commanded to change phases multiple times during connection. In this case, the switching elements are represented through three single phase breakers added at the terminals of each PHEV charger, which allows each individual PHEV charger to be automatically connected to any of the three phases based on the commanded phase. When a commanded phase is sent from the algorithm to the set of three single phase breakers connected to a PHEV charger terminals, all of the breakers open except for the one attached to the commanded phase, which is triggered to close. Switches consisting of power electronics could also be used in place of breakers.

\section{Results}

Using the system described in Section 3, the real power balancing algorithm is applied to the connected car park. The real power measured that the algorithm will attempt to balance is flowing into the bus where the car park is connected. This bus feeds both the car park as well as other downstream loads, which are the original source of unbalance in the feeder. Figure 3 shows the real power flowing into the bus both before and after the balancing algorithm is applied. For the first half of the time shown, the balancing algorithm is not applied and PHEVs are connected according to Table 2. After the first half of the time shown, the balancing algorithm is applied and PHEVs are assigned to phases in such a way as to balance the real power flowing into the bus. As can be seen in Figure 3, applying the real power balancing algorithm to the car park almost perfectly balances the real power flowing into the bus. This balancing is accomplished by switching vehicles from the heavily loaded phases, A and $\mathrm{B}$, to the lightly loaded phase, C. Table 3 shows the powers for each phase and maximum percent difference both before and after balancing occurs, as measured at the car park bus. This in turn has the effect of pushing the entire system towards a more balanced operation, as can be seen in Figure 4. At this bus, the load on the two heavily loaded phases, A and B, is again reduced and the load on the lightly loaded phase, C, is increased by approximately the same amount of the reductions of the other two phases. Table 4 shows the powers for each 


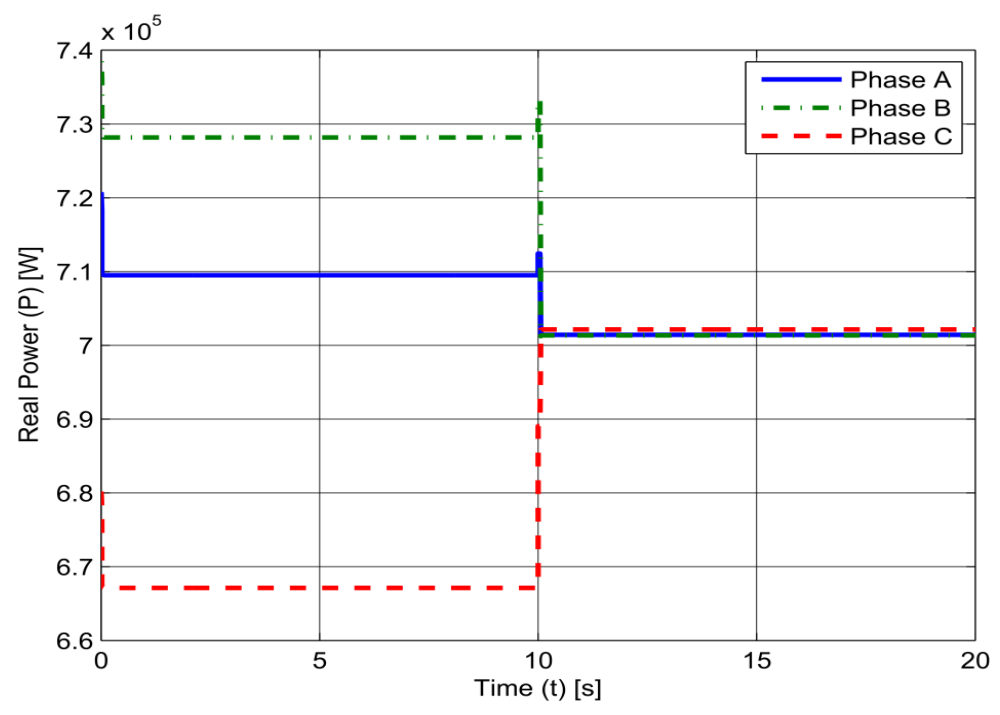

Figure 3. Results of real power balancing algorithm—car park bus.

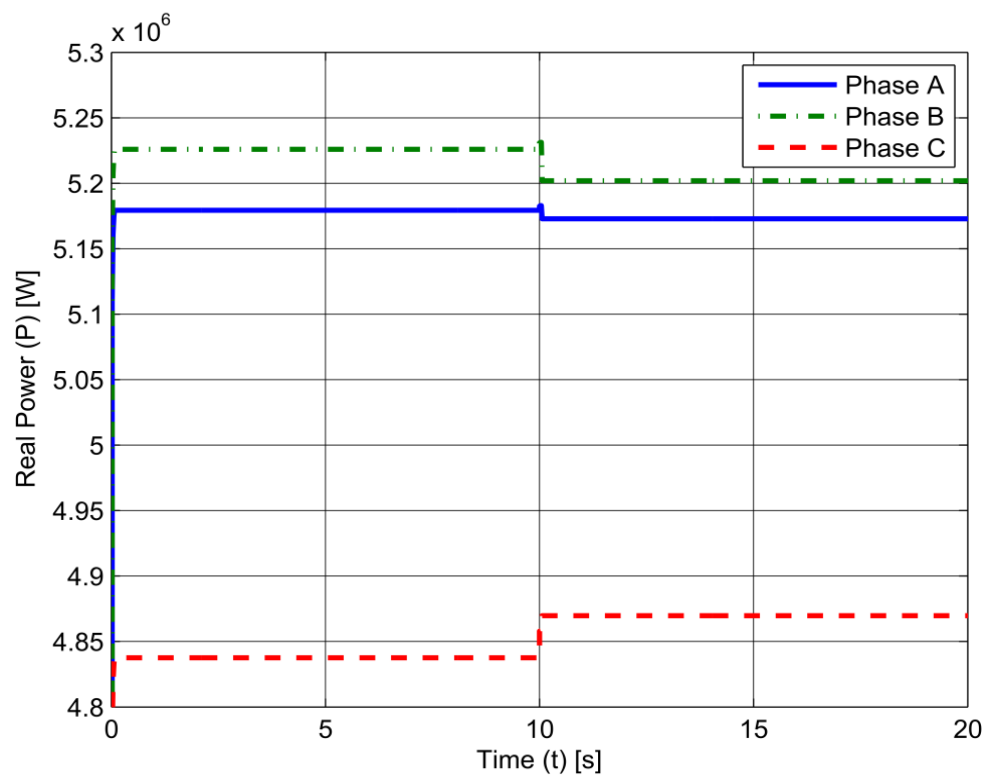

Figure 4. Results of real power balancing algorithm—utility feed.

Table 2. Initial PHEV phase connections.

$$
\text { PHEV number }
$$

$1,4,7,10,13,16,19,22,25,28$
$2,5,8,11,14,17,20,23,26,29$
$3,6,9,12,15,18,21,24,27,30$
Connected phase
A
B
C

Table 3. Results of real power balancing algorithm—car park bus.

\begin{tabular}{ccccc}
\hline Case & Phase A power & Phase B power & Phase C power & Maximum percent difference \\
\hline Before balancing & $709.5 \mathrm{~kW}$ & $728.2 \mathrm{~kW}$ & $667.1 \mathrm{~kW}$ & $8.758 \%$ \\
After balancing & $701.4 \mathrm{~kW}$ & $701.3 \mathrm{~kW}$ & $702.2 \mathrm{~kW}$ & $0.128 \%$ \\
\hline
\end{tabular}


phase and maximum percent difference both before and after balancing occurs, as measured at the utility feed.

During normal operation of distribution systems, many loads may vary frequently. In order to be practical for real world applications, the algorithm must be able to adapt to load variations. The algorithm's ability to keep up with these variations can be seen in Figure 5. In this figure, the first half of the time shown is the same power as is shown in the second half of Figure 3. During this period, the real power balancing algorithm has been applied. At halfway through the time shown, the load is instantaneously changed. At this point, the balancing algorithm keeps the PHEVs connected to the same phases as before the load change for 10 seconds. This is the time between balancing calculations selected for this algorithm. Therefore this represents the longest time between a system change and recalculation to assign a new phase configuration. After this point, the balancing algorithm runs again and the phase assignments of the PHEVs are switched in order to better balance the system. Figure 6 extends the changing load profile for all 24 hours in the day, where each hour is represented by the first 20 seconds of data for that hour's simulation. It should be noted that Figure 5 and Figure 6 are the results of multiple simulations plotted one after the other due to limitations on changing load values in Sim Power Systems during a simulation. After the first simulation, the initial values for PHEV phase connections and powers in the simulations are taken from the results of the prior simulation however.

\section{Conclusion}

It has been successfully shown that this new idea will enable PHEV charging and discharging to have a positive impact on a distribution system by reducing real power unbalance. The phase balancing algorithm assigns each PHEV to an individual phase based on the real power that the charger draws or supplies. The presented algorithm correctly operates for both charging and discharging PHEVs. By changing the phase without altering the power of each charger, the system is able to benefit while PHEV owners will see almost no change in operation compared with a charger that has a static phase connection. It is also possible to connect or disconnect PHEVs from the system at any time and it will recalculate a new phase assignment to move towards a balanced system.

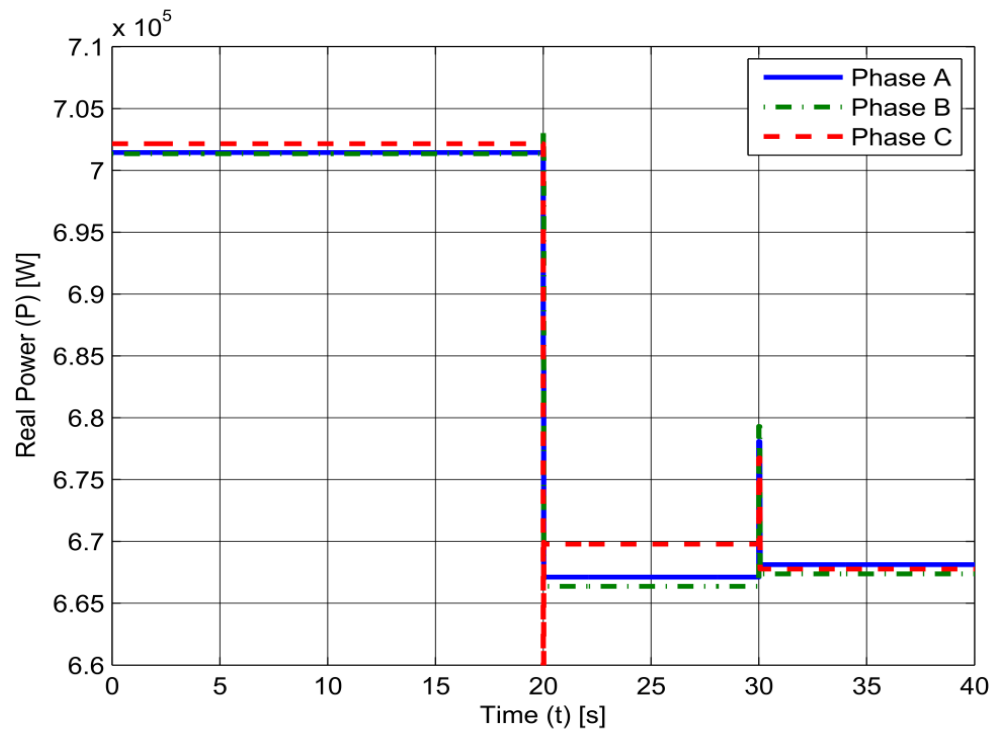

Figure 5. Results of real power balancing algorithm under changing loadcar park bus.

Table 4. Results of real power balancing algorithm—utility feed.

\begin{tabular}{ccccc}
\hline Case & Phase A power & Phase B power & Phase C power & Maximum percent difference \\
\hline Before balancing & $5.18 \mathrm{MW}$ & $5.23 \mathrm{MW}$ & $4.84 \mathrm{MW}$ & $7.711 \%$ \\
After balancing & $5.17 \mathrm{MW}$ & $5.20 \mathrm{MW}$ & $4.87 \mathrm{MW}$ & $6.593 \%$ \\
\hline
\end{tabular}




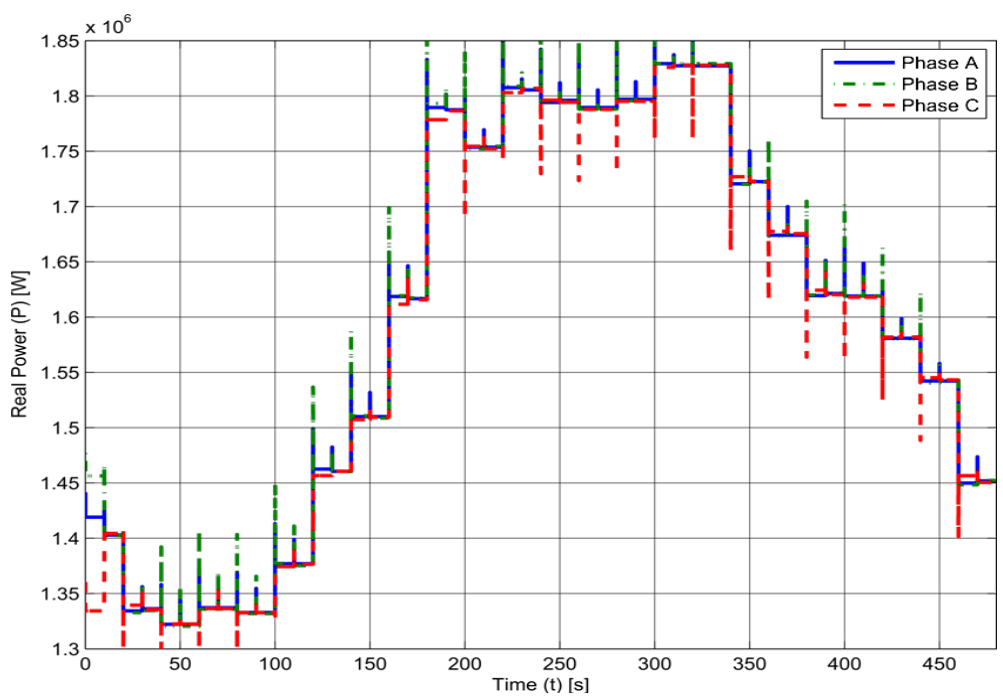

Figure 6. Results of real power balancing algorithm under changing load, daily load profile-car park bus.

\section{Acknowledgements}

The authors would like to thank the members of the Clemson University Electric Power Research Association (CUEPRA) for their financial support and valuable discussion.

\section{References}

[1] Oe, S.P., Christopher, E., Sumner, M., Pholboon, S., Johnson, M. and Norman, S.A. (2013) Microgrid Unbalance Compensator-Mitigating the Negative Effects of Unbalanced Microgrid Operation. 4th IEEE/PES Innovative Smart Grid Technologies Europe (ISGT EUROPE), 6-9 October 2013, 1-5.

[2] Dharmakeerthi, C.H., Mithulananthan, N. and Saha, T.K. (2011) Overview of the Impacts of Plug-In Electric Vehicles on the Power Grid. IEEE PES Innovative Smart Grid Technologies Asia (ISGT), 13-16 November 2011, 1-8.

[3] Chindris, M., Cziker, A., Miron, A., Balan, H., Iacob, A. and Sudria, A. (2007) Propagation of Unbalance in Electric Power Systems. 9th International Conference on Electrical Power Quality and Utilisation, 9-11 October 2007, 1-5.

[4] Makram, E., Zambrano, V., Harley, R. and Balda, J. (1989) Three Phase Modeling for Transient Stability of Large Scale Unbalanced Distribution Systems. IEEE Transactions on Power Systems, 4, 487-493. http://dx.doi.org/10.1109/59.193820

[5] Anumolu, P., Banhazl, G., Hilgeman, T. and Pirich, R. (2008) Plug-In Hybrid Vehicles: An Overview and Performance Analysis. IEEE Long Island Systems, Applications and Technology Conference, 2 May 2008, 1-4.

[6] Kisacikoglu, M.C., Ozpineci, B. and Tolbert, L.M. (2010) Examination of a PHEV Bidirectional Charger System for V2G Reactive Power Compensation. 25th Annual IEEE Applied Power Electronics Conference and Exposition (APEC), 21-25 February 2010, 458-465.

[7] Clarke, A.D., Bihani, H.A., Makram, E.B. and Corzine, K.A. (2014) Analysis of the Impact of Different PEV Battery Chargers during Faults. Journal of Power and Energy Engineering, 2, 31-44. http://dx.doi.org/10.4236/jpee.2014.28004 
Scientific Research Publishing (SCIRP) is one of the largest Open Access journal publishers. It is currently publishing more than 200 open access, online, peer-reviewed journals covering a wide range of academic disciplines. SCIRP serves the worldwide academic communities and contributes to the progress and application of science with its publication.

Other selected journals from SCIRP are listed as below. Submit your manuscript to us via either submit@scirp.org or Online Submission Portal.
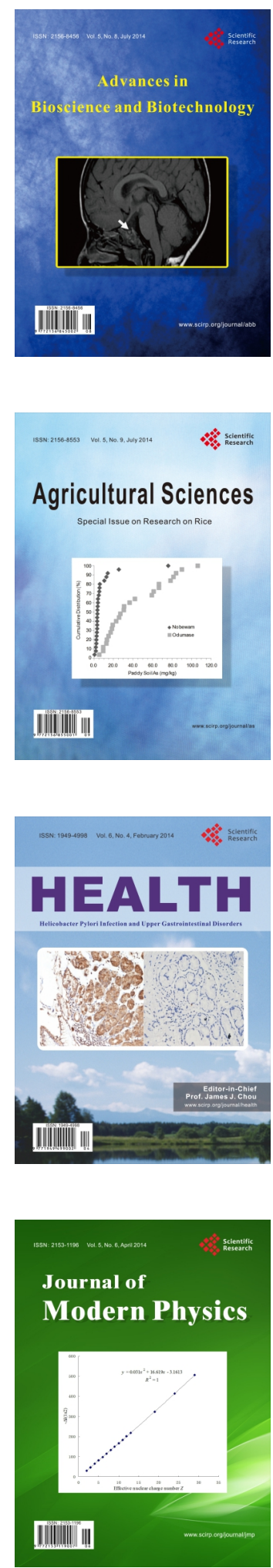
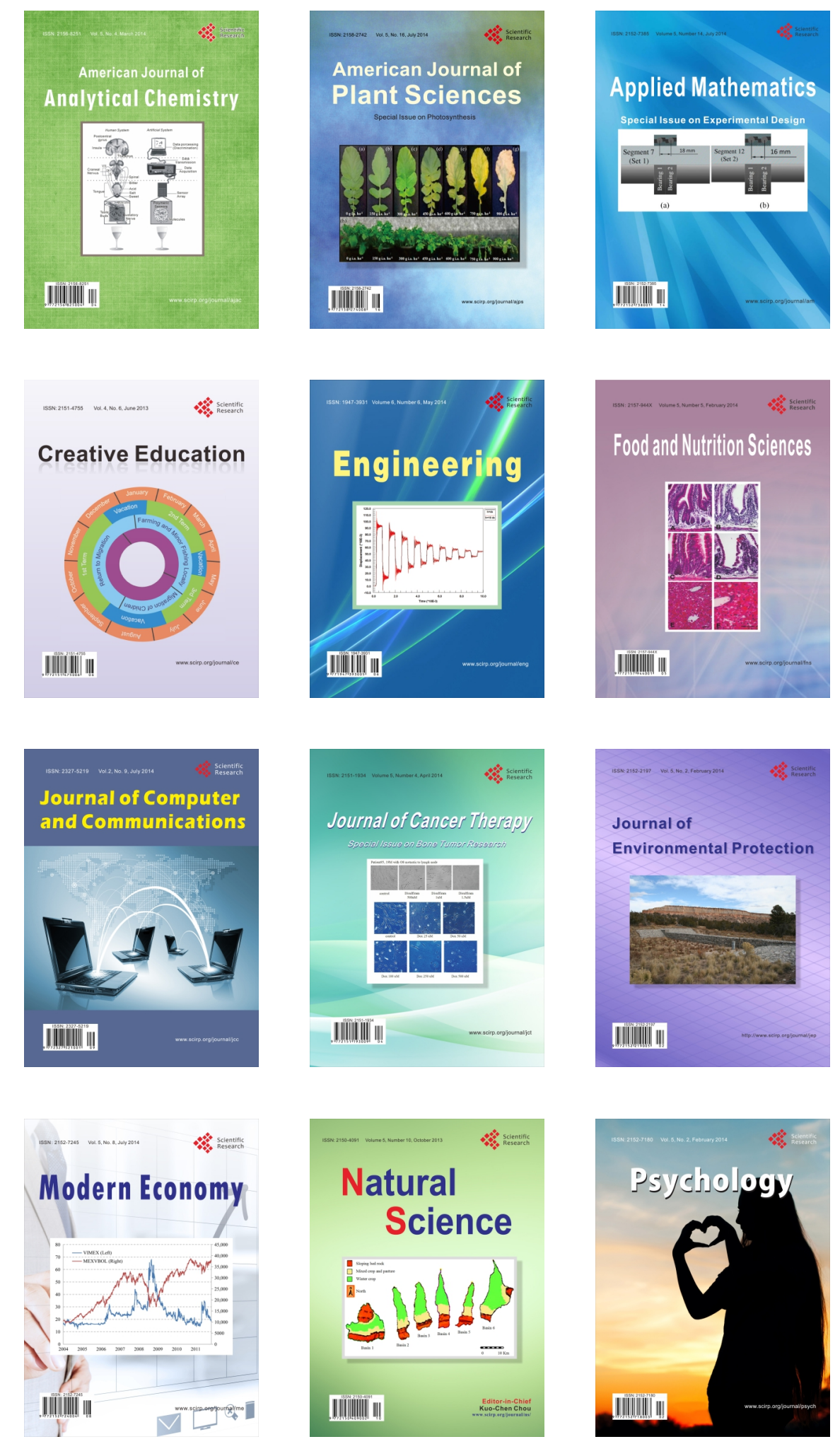